The other contributions to the meeting concerned the study of pyrolysis products. Dr. J. Girling described studies on the identification of the primary products of the pyrolysis of coal, in which field the introduction of gas chromatography has enabled the scale of experiments to be reduced from $20 \mathrm{kgm}$. to $20 \mathrm{mgm}$. A $20-\mathrm{mgm}$. sample is heated to a series of steady temperatures ranging from $50^{\circ}$ up to $700^{\circ} \mathrm{C}$. and the products of pyrolysis at each temperature are swept into a refrigerated trap. The analytical sample is injected on to the column, containing polyethyleneglycol or squalane, by means of an automatic valve of $0.1 \mathrm{ml}$. capacity; there was considerable interest in the design of this valve, the fixed sample volume of which is formed by a length of $1-\mathrm{mm}$. bore nylon tubing between two sections of the tubing which are compressed by cam-operated plungers. Dr. J. Blenkin described the analysis of hydrocarbon elastomers by combined pyrolysis and gas chromatography. It was hoped that elastomers could be identified if the monomers from which they are made could be obtainod from them and analysed by gas chromato. graphy : to a large extent this hope has been realized. Samples are pyrolysed by dropping them into a heated silica tube attached to the apparatus, so that the products of pyrolysis are swept into the column and chromatographed; for example, polybutadiene gives a chromatogram of butadiene, natural rubber one of a mixture of isoprene and dipentene. Dr. Lehrle described similar experiments in which the degrada. tion was carried out in stages. A sample is placed in a coil of resistance wire in the form of a basket which is located at the entrance to the column. The tempera. ture of the wire is varied by altering the current passing through it, and within half an hour a series of chromatograms can be obtained corresponding to the degradation of the one sample at each temperature. The series of chromatograms is characteristic and suitable for qualitative and quantitative analysis.

The symposium concluded with a general discussion on sample injection, which was introduced by Dr. Purnell. Most speakers were agreed on the difficulty, if not present impossibility, of injecting representative samples for quantitative analysis which are small enough to be satisfactory with ionization detectors. The lower limit of sample introduction possible with pipettes and syringes is probably about 25 micrograms. Various suggestions-for designs of valves or introduction of the sample in solution-were made, but the simplest proposal for quantitative analysis was made by Dr. A. B. Littlewood, namely, to use a large sample and correspondingly insensitive detector. D. Ambrose

\title{
MEDICAL RESEARCH IN MALAYA
}

$T$ HE valuable research work being done in the vast field of tropical medicine is well brought out in the annual report of the Institute for Medical Research, Federation of Malaya, for 1958.

The Institute is divided into a number of divisions, each of which is carrying out investigations into diseases which are baffling and wide-spread. In the Pathology Division, for example, a curious type of allergic granuloma, apparently hitherto undescribed and believed to be the result of an auto-immunity reaction, has been investigated for some years. The variations in the behaviour of melanocytes when surrounded by atypical or malignant epidermal cells have also been studied.

A number of important investigations are being made in the Division of Nutrition and Biochemistry. Severe anæmia is one of the main complications of pregnancy in Asian women, and one in eight of the beds available for ante-natal patients in the General Hospital, Kuala Lumpur, is occupied by a patient requiring treatment for anæmia. Premature births, deaths of infants and of mothers were all increased in this group of women.

The relationship of hookworm infection to anæmia was also studied : the greater the degree of anæmia, the higher was the proportion of patients with hookworm infection. The use of radioactive chromium enabled calculations of the daily loss of blood apparently due to hookworms ; with heavy infections this could amount to as much as $80 \mathrm{ml}$. (almost $3 \mathrm{fl}$. oz.) of blood a day. Other studies were made on the changes in blood volume in chronic anæmia, on the factors influencing response to treatment, and on the reasons for the frequent low levels of vitamin $B_{12}$ to be found in patients with megaloblastic anæmia.

Dietary inquiries made in the homes of a number of the patients indicated that various causes, besides poverty, were responsible for the poor diets which finally resulted in their admission to hospital with nutritional anæmia.

In almost every area where sufficient numbers of 'toddlers', children aged 1-4 years, have been examined, examples of protein malnutrition can be found; this is true even in the heart of Kuala Lumpur. Only a few come to hospital; they must be sought out by home visits and detailed inquiries. As might be expected, the condition is most common in isolated areas where communications are poor and unemployment is prevalent. A detailed investigation was made of kampongs on the Perak River where protein malnutrition is common; the diets there were found to be most unsatisfactory, and well below the recommended allowances.

In the Bacteriology and Serology Division, research activities were directed to the production of vaccines to combat epidemics of cholera and smallpox.

The search for Malayan streptomyces which may produce antibiotics continued, but without success ; resistance of bacteria to the commonly used antibiotics is becoming more noticeable.

Resistance to the tubercle bacillus is now reaching the point where it presents a serious problem. Judging by sensitivity tests, about 10 per cent of local strains are completely resistant to streptomycin, about 10 per cent are resistant to $p$-aminosalicylate, and 2 per cent to isoniazid. Partial resistance to one or other of these drugs is found in $30-50$ per cent of strains tested.

The Virus Research and Medical Zoology Division continued its work on arthropod-borne and other viruses. Further work was done on the survey of animal reservoirs of leptospirosis, and infected rats were obtained from Maxwell Hill in Perak, from Langkawi Island, and from parts of Trengganu. By 
contrast, no infections were found in much larger numbers of rats from Selangor coastal region. A new development, still being investigated, was the finding of evidence of frequent infection in one but not another species of water-snake in Kuala Lumpur streams.

Leptospirosis in humans is now recognized as being much more common than had been suspected a few years ago, and the virus laboratory is at present trying to assess the diagnostic value of a relatively simple test, suitable for use in a routine laboratory.

At the request of the World Health Organization, the Entomology Division carried out tests to assess the merits of two types of apparatus in which mosquitoes are held for short periods against surfaces treated with insecticide, and the kill later recorded. The opportunity was taken to include the organo-. phosphorus compound, malathion, in these tests : the duration of effectiveness proved to be about three months, which was longer than had been expected. The importance of this finding is that malathion has had to be used to control bed bugs which have developed resistance to the usual residual insecticides, especially dieldrin. Reports of such resistance were received from three rubber estates and a small mental hospital, and malathion is reported to have given satisfactory results.

An incidental result of house-spraying with dieldrin has been the virtual elimination of head-lice in the children living in the sprayed houses. Whereas in unsprayed areas infestation-rates in both boys and girls were 70-90 per cent, no active infestation could be found in the children where spraying had been carried out for one year.

Other work done at the Institute was by the U.S. Army Medical Research Unit, Malaya. The unit investigated two outbreaks of scrub typhus in the Commonwealth Forces in some detail. One in central Perak, near Ipoh, was unusual in that the disease was mild, the Weil-Felix reactions were negative, and cases occurred in forest during the dry season instead of in scrub terrain in the wet season. Rickettsiae, however, were isolated in mice inoculated with blood from several patients, and they appear to belong to the scrub typhus group. Cases from the other outbreak in south-east Johore were typical in nature, and Weil-Felix tests were positive.

The report may be obtained from the Director of Medical Research, Federation of Malaya, Kuala Lumpur.

\section{SURFACE TEMPERATURE OF SWEDISH LAKES AND THE ORIGIN OF RAINFALL}

\section{BY VILHELM IRGENS PETTERSSON* \\ Bollstavägen 10, Enskede, Sweden}

\section{The Dry Summer of 1959}

$\mathrm{T}$ HE accompanying diagrams (Figs. 1-4) give the distribution of rainfall over Sweden as a percentage of the normal in 1959 (published by the Meteorological and Hydrological Institute of Stockholm). They show very clearly that in the summer of 1959 Sweden shared the scarcity of rainfall characterizing the weather over most of north-western Europe, although it varied from place to place. As will be seen, the whole inland area, generally speaking, with its half-dried-out rivers and reduced. rops, is framed in by belts of moisture along the coasts and the Norwegian and the Finnish borders, broadening to their maximum in the north.

The period of deficit in rainfall over the major part of Sweden lasted for the five months MaySeptember, according to the monthly surveys of the Meteorological and Hydrological Institute in Stockholm, from which the following data are cited :

May. Total precipitation averaged 87 per cent of normal, with sub-variations of 300 per cent in the north down to 10 per cent in the south.

June. Total precipitation averaged 61 per cent of normal with sub-variations of surplus in the north and deficit in the south with its minimum in the middle south-west.

July. Precipitation in general 72 per cent of normal with a minimum of 10-25 per cent in the northern Baltic coast-land.

August. Precipitation in general 41 per cent of normal ; 100 per cent only in limited areas in farthest north and south.

* Formerly of the Service Hydrographique in Copenhagen and editor of its Bulletin Trimestriel.
September. Precipitation as total average 53 per cent of normal except along the northern part of the Norwegian border, and in a belt running east-west. from south of Lake Vänern to the coast south of Stockholm with a rainfall 100-200 per cent of normal.

Note. In the following, temperatures are in degrees centigrade, distances and depths are in kilometres and metres respectively; surface temperatures were measured $0 \cdot 5-1 \cdot 0 \mathrm{~m}$. beneath the surface.

\section{Rainfall South of lat. $59^{\circ} 30^{\prime}$ N. and Deviations in Temperature from the Average during July- September 1959}

In this part of Sweden the landscape is dominated by the two big lakes, Lake Vänern with an area of $5,500 \mathrm{~km} .{ }^{2}$, and Lake Vettern with an area of 1,900 $\mathrm{km} .{ }^{2}$.

July (Fig. 1). The average temperature was $2^{\circ}-$ $2 \cdot 5^{\circ}$ above normal; precipitation 100 per cent and more only in the south inside a triangular area with its base along the orresund and farther east to the south point of the island of öland, reaching up to the south end of Lake Vettern; this lake, together with the north part of Lake Vänem falling inside the contour for 50-75 per cent of rainfall, the south part of Lake Vänern again being inside a region of almost total dryness.

August (Fig. 2). Average temperature was $2^{\circ}-3^{\circ}$ above normal. Precipitation was 10-50 per cent of the average. It was up to normal only in isolated areas, one of them around the south end of Lake Vettern whereas Lake Vänern registered 25 per cent and less. 